\title{
VISIBILITY IN BLOWING SNOW OBSERVED BY THE LUMINANCE CONTRAST
}

\author{
by
}

\author{
KEISHI ISHIMOTO AND YoSHIFUMI FUKUZAWA
}

Civil Engineering Research Institute, Hokkaido Development Bureau, Hiragishi 1-3, Sapporo, Japan 062

\begin{abstract}
The effect of surrounding luminance on visual range in blowing snow condition was investigated in daytime, by comparing visibility derived from luminance contrast with that derived from transmissivity observed simultaneously. A volume of air sampled for monitoring may not accurately represent the atmosphere from which it was taken. Differences in measurements through two types of visibility meters increased from daytime to twilight, and with cloudy or lightly blowing snow conditions in daytime. In heavy blowing snow, visual range measured by transmissivity coincided with that by luminance contrast.

We was concluded that visual range obtained by transmissometer was inclined to be over-estimated in
\end{abstract} conditions of cloud and light blowing snow.

\section{INTRODUCTION}

Visibility meters for daytime use may be separated into two broad classes. One includes devices which can monitor the brightness contrast between an object and the surroundings (luminance meters). The other includes devices which monitor a limited volume of air (eg transmissometers). The latter are more popular than the former because they are easy to operate for continuous monitoring, and have a clear theoretical background (Takeuchi 1980).

Visual range is defined as the greatest distance at which an object can be seen and identified. In accordance with Koschmieder's theory, the apparent brightness of a black object, with baffles covered by black cloth, was compared simultaneously with the apparent brightness of background sky near the target, and the visual range was derived. Visual range through a transmissometer was monitored on plane snow surface where there was no obstruction within $800 \mathrm{~m}$ upwind.

\section{EXPRESSION FOR VISUAL RANGE}

If the luminance of the target is $\mathrm{B}_{\mathrm{d}}$ and that of the background is $B_{h}$, the contrast $C$ is defined as

$$
C=\left[B_{d}-B_{h}\right] / B_{h}
$$

$\mathrm{B}_{\mathrm{d}}=$ luminance of the object $\mathrm{dm}$ separate from the luminance meter. $\mathrm{B}_{\mathrm{h}}=$ horizontal background luminance.

A black box $\left(C_{0}=-1\right)$ was used as the target object located $30 \mathrm{~m}$ from the luminance meter. Duntley (1948) expressed the contrast attenuation as

$$
\frac{C}{C_{O}}=e^{-\sigma d}
$$

$\sigma$ : light attenuation coefficient.

Koschmieder (1925) defined the visual range (V) as the distance at which the brightness contrast reached the liminal value $(\epsilon=0.05$, in highway meteorology).

$$
\epsilon=0.05=\mathrm{e}^{-\sigma v}
$$

Consequently, the visual range $\mathrm{V}(\mathrm{m})$ was derived from the brightness contrast as

$$
V=-90 \frac{1}{\log _{e}\left[\frac{B_{h}-B_{d}}{B_{h}}\right]}
$$

$\mathrm{d}=$ distance from luminance meter to the target $(30 \mathrm{~m})$. Whereas Bouguer's law expressed the light attenuation coefficient as

$$
\sigma=\frac{1}{\mathrm{~d}} \log _{\mathrm{e}} \frac{1}{\mathrm{~T}}
$$

$\mathrm{T}=$ transmissivity.

The visual range through the transmissometer is

$$
\mathrm{V}=-90 \frac{1}{\log _{\mathrm{e}} \mathrm{T}}
$$

path length, $d=30 \mathrm{~m}$.

The transformations of equations were mentioned by Middleton (1952). A pair of luminance meters (visual angle $0.2^{\circ}$ ) with relative luminous efficiency of the human eye were used to measure luminances of the background and the target respectively. The human eye is more sensitive in the lower visual range. The expected lowest visual range was about $100 \mathrm{~m}$, and the relative error is

$$
\frac{\Delta V}{V}=\frac{1 / T}{\log _{e}(1 / T)} \Delta T=\frac{e^{3} d / V}{3 d / V} \Delta T,
$$

If $\Delta \mathrm{T}=$ preset accuracy, one can show that $\Delta \mathrm{V} / \mathrm{V}$ has a minimum at $3 \mathrm{~d} / \mathrm{V}=1$; consequently the base line should be of the order of $1 / 3$ of the expected visual range. The path length of the transmissometer was $30 \mathrm{~m}$. COMPARISON OF MEAN VUSUAL RANGES FROM
DAYTIME TO TWILIGHT

Luminance of the background depends on the altitude of sun and weather conditions. Mean visual range (every 10 minutes) was observed from daytime to twilight on 22 February 1983.

Visual range determined by the two methods is shown in Figure 1. The visual range difference was not large in heavy blowing snow in daytime. However, the difference increased in light blowing snow conditions. From daytime to twilight, the light blowing snow intensity gradually decreased, while at the same time the visual range difference increased and was observed to increase rapidly before and after sunset. It is assumed that the difference in

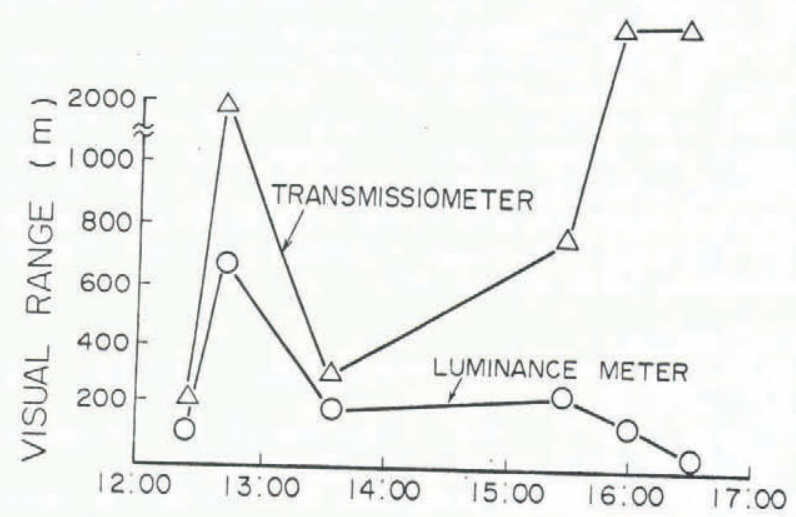

Fig.1. Mean visual range variation as a function of time of 
daytime depends on weather conditions, including the degree of atmospheric uniformity.

\section{DIFFERENCE OF VISUAL RANGES IN DAYTIME WITH BLOWING SNOW}

Daytime visual range derived from luminance contrast was compared precisely with that derived from transmissivity in blowing snow under partly cloudy sky between 12:17 and 12:27 hrs on 22 February 1983. Mean visual ranges at $75 \mathrm{~cm}$ above the snow surface through the transmissometer and luminance meter were $650 \mathrm{~m}$ and 200 $\mathrm{m}$ respectively. Mean wind speed at same level was $7.5 \mathrm{~m} / \mathrm{s}$, and the visual range dropped below $100 \mathrm{~m}$ several times with precipitation.

The shadow of a pole was recognized occasionally. Black cloud was scattered above the horizon. The luminance of background variated from $5000 \mathrm{~cd}$ (candela) to $20000 \mathrm{~cd}$. Data through the transmissometer and luminance meter were sampled at intervals of 0.1 seconds from magnetic tapes simultaneously and compared with each other.

The visual ranges from the two types of visibility meters are illustrated in Figure 2. It can be seen that the visual range through the transmissometer was usually greater than that through the luminance meter.

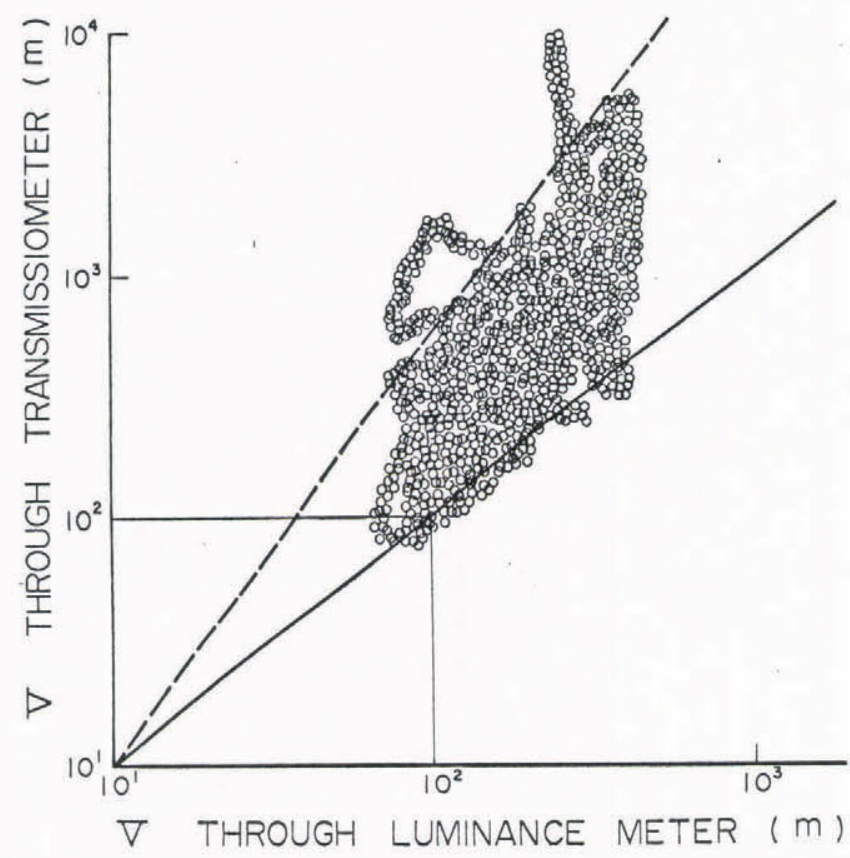

Fig.2. The difference of visual ranges through the transmissometer and through a pair of luminance meters.

\section{CONCLUSION}

In accordance with the definition of visual range, the apparent brightness of the target black box was compared with the apparent brightness of the sky above the horizon. The estimated visual range was compared simultaneously with visual range through the transmissometer.

Thus field observations showed that the visual range through the transmissometer gave a sampling error in light blowing snow because atmospheric uniformity had a tendency to disappear and the variation of background luminance increased. This tendency is inevitable in all equipment which monitors a small volume of air (Johnson 1954). However, visual range measured by the two methods coincided in heavy blowing snow.

\section{REFERENCES}

Johnson J C 1954 Physical meteorology. Cambridge, The MIT Press: 65-101

Middleton W E K 1952 Vision through the atmosphere. Toronto, University of Toronto Press: 6-132

Takeuchi M 1980 [Investigation of visibility in snow storm.] Hokkaido Development Bureau Civil Engineering Research Institute Report 74 (In Japanese: English abstract) 